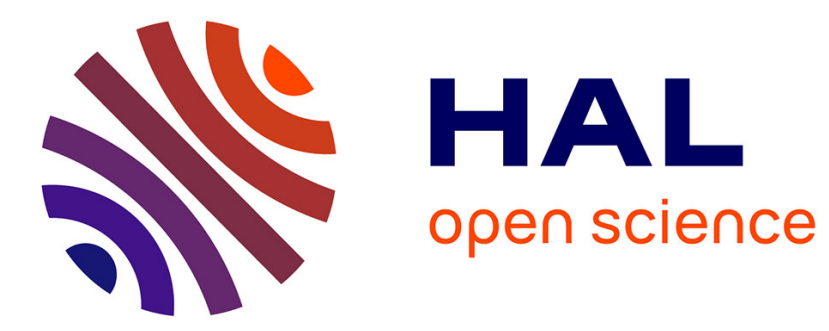

\title{
Taxes and subsidies in vertically related markets
}

Marion Desquilbet, Hervé Guyomard

\section{To cite this version:}

Marion Desquilbet, Hervé Guyomard. Taxes and subsidies in vertically related markets. 15. journées de microéconomie appliquée, Jun 1998, Pointe-à-Pitre, France. 26 p. hal-02283455

\section{HAL Id: hal-02283455 \\ https://hal.science/hal-02283455}

Submitted on 7 Jun 2020

HAL is a multi-disciplinary open access archive for the deposit and dissemination of scientific research documents, whether they are published or not. The documents may come from teaching and research institutions in France or abroad, or from public or private research centers.
L'archive ouverte pluridisciplinaire HAL, est destinée au dépôt et à la diffusion de documents scientifiques de niveau recherche, publiés ou non, émanant des établissements d'enseignement et de recherche français ou étrangers, des laboratoires publics ou privés.

\section{(a)(1) $\$$}

Distributed under a Creative Commons Attribution - NonCommercial - NoDerivatives| 4.0 
15èmes Journées de micro-économie appliquée

04-05 Juin 1998

Pointe à Pitre

INRA - ECONOMIE

BIBLIOTHEQUE

Rue Adolphe Bobierre

CS 61103

35011 RENNES CEDEX

Tél. 02.99.28.54.08

Taxes and subsidies in vertically related markets

Marion Desquilbet, Hervé Guyomard

\author{
INRA ESR \\ 65 rue de St Brieuc \\ 35042 Rennes cedex, France
}

Tél : 0299285382

Fax : 0299285380

Adresses électroniques et téléphone des auteurs :

desquilb@roazhon.inra.fr, 0299287208 
hguyomar@roazhon.inra.fr, 0299285387

Marion Desquilbet, Hervé Guyomard

INRA ESR, 65 rue de St Brieuc, 35042 Rennes cedex.

\section{Taxes and subsidies in vertically related markets ${ }^{1}$}

In the framework of a two country, two good, sector-specific factor partial equilibrium model where one of the goods (the bulk commodity) is an intermediate input in production of the second good, we assume that the government wishes to transfer income either to bulk commodity producers, or to both bulk commodity and processed good producers. Our analysis is concerned with efficient redistribution, the instruments considered are subsidies and/or taxes, and there exists an opportunity cost of public funds. We show how the principle of targeting can be used to characterize the full set of optimal subsidies and/or taxes applied on both the bulk commodity and the final good in this vertically integrated market structure.

\section{Introduction}

In almost every industrialized country governments intervene in the production and marketing of agricultural goods in order to stabilize prices and redistribute income from consumers and/or taxpayers to farmers. In a one good partial equilibrium setting, the outcome of efficiency comparisons between various combinations of price and quantity policy instruments depends on underlying parameters (supply and demand elasticities), the size and openness of the economy, the size of the desired income redistribution as well as the size of the excess burden of taxation (see, e.g., Wallace, Gardner, Alston and Hurd, Alston et al. 1993, Moschini and Sckokai). ${ }^{2}$

In this paper, we follow the previous line of research by assuming that the government seeks to minimize welfare losses due to intervention subject to the constraint that total rent to 
agricultural producers must be as large as a given income target and by considering that deadweight costs of taxes elsewhere in the economy are too important to be ignored (Alston and Hurd, Alston et al. 1993, Moschini and Sckokai). We differ from the studies quoted above by recognizing that "agricultural" goods currently subsidized are bulk commodities as well as final commodities which process these bulk commodities. We thus extend the existing literature by integrating the three following points into the analysis. First, most agricultural goods are processed before final consumption. Second, most agricultural policies apply to both the bulk and the processed agricultural good stages. Third, the central objective of support of the agricultural revenue is often accompanied by an objective of revenue compensation directed towards processors - mainly because agribusiness interest groups are politically powerful and active in the policy-making process in which farm programs are decided (Alston et al. 1989).

The example of processed cereals in the European Union (EU) and in the United States (US) illustrates this third point. In the EU, where the internal price of cereals is above the world price, processed products made from grains benefit from trade protection. The level of export refunds on these processed products (mainly wheat flour and malt) is notably determined according to the content in cereals and the difference between the internal price and the world price of cereals, which corresponds to an objective of compensation of processors for the overcost of the intermediate good (i.e. cereals). They are also determined according to "outlets and conditions of sale of processed products on the world market" (CAP Monitor, 1997, p. 10A-26). This leaves an important room for maneuver to public decision-makers, so that the subsidy policy may more than compensate processors. Similar protection mechanisms are present in the EU pork and poultry sectors, where the intervention policy explicitly takes into 
account the "processed cereal" characteristic of these animals, thus the insights of our model apply to these sectors as well.

In the case of the US, the pre 1996 Fair Act policy in the grain sector mainly amounted to a producer subsidy. When the Export Enhancement Program was introduced, it was first applied on bulk commodities (wheat), and it was later extended to include flour and other processed goods. This last situation corresponds to the case where there is an income transfer to both farmers and HVP producers.

The analysis of policy intervention in two vertically related bulk and processed agricultural good markets has already been the focus of several works (e.g. Alston et al. (1989) in a closed economy, Chambers (1983) and Paarlberg in a two-country framework). While the corresponding papers are centered on comparative static effects, our analysis is concerned with second rank optimality of intervention in presence of a redistribution constraint. We consider efficient redistribution, first to bulk commodity producers in terms of minimizing the total costs to consumers, taxpayers and final good producers of achieving a given increase in farmer surplus, second to both bulk commodity and final good producers in terms of minimizing the total costs to consumers and taxpayers of achieving a given increase in both farmer and final good producer surplus.

Our analysis relies on a two country, two good, sector-specific factor partial equilibrium model. We consider only subsidy and tax instruments and we exclude, in particular, lump-sum transfers, decoupled payments and production quotas. To account for deadweight losses of taxation in this partial equilibrium framework, we assume an exogenous and constant marginal excess burden of taxation (Alston and Hurd). Following Paarlberg, we assume the home country exports the agricultural product as well as the HVP which uses the agricultural product as an intermediate input. 


\section{Analytical framework}

\section{Notations and definitions}

In the home country $(\mathrm{H})$ the bulk commodity 1 is produced with a variable input $x$ and a specific factor $K_{1}$. The bulk commodity is used as an input into the processing sector producing good 2, combined with the variable input $x$ and a specific factor $K_{2}$. The two goods are produced under competitive conditions using technologies with constant returns to scale, with the variable input perfectly elastic in supply and the two specific factors perfectly inelastic in supply. The price $w$ of the variable input is exogenous and the two industries are profit maximizers. The home country exports both the bulk commodity and the processed good, while the foreign country (F) imports both goods. There is no public intervention in the foreign country where technologies are of the same type and variables are denoted with an asterisk. Let $p s_{i}$ and $p d_{i}$ denote supply and demand prices in the home country, and $p_{i}^{*}$ ( $i=1,2$ ) the corresponding world prices. The following graphic summarizes the structure of the model. 


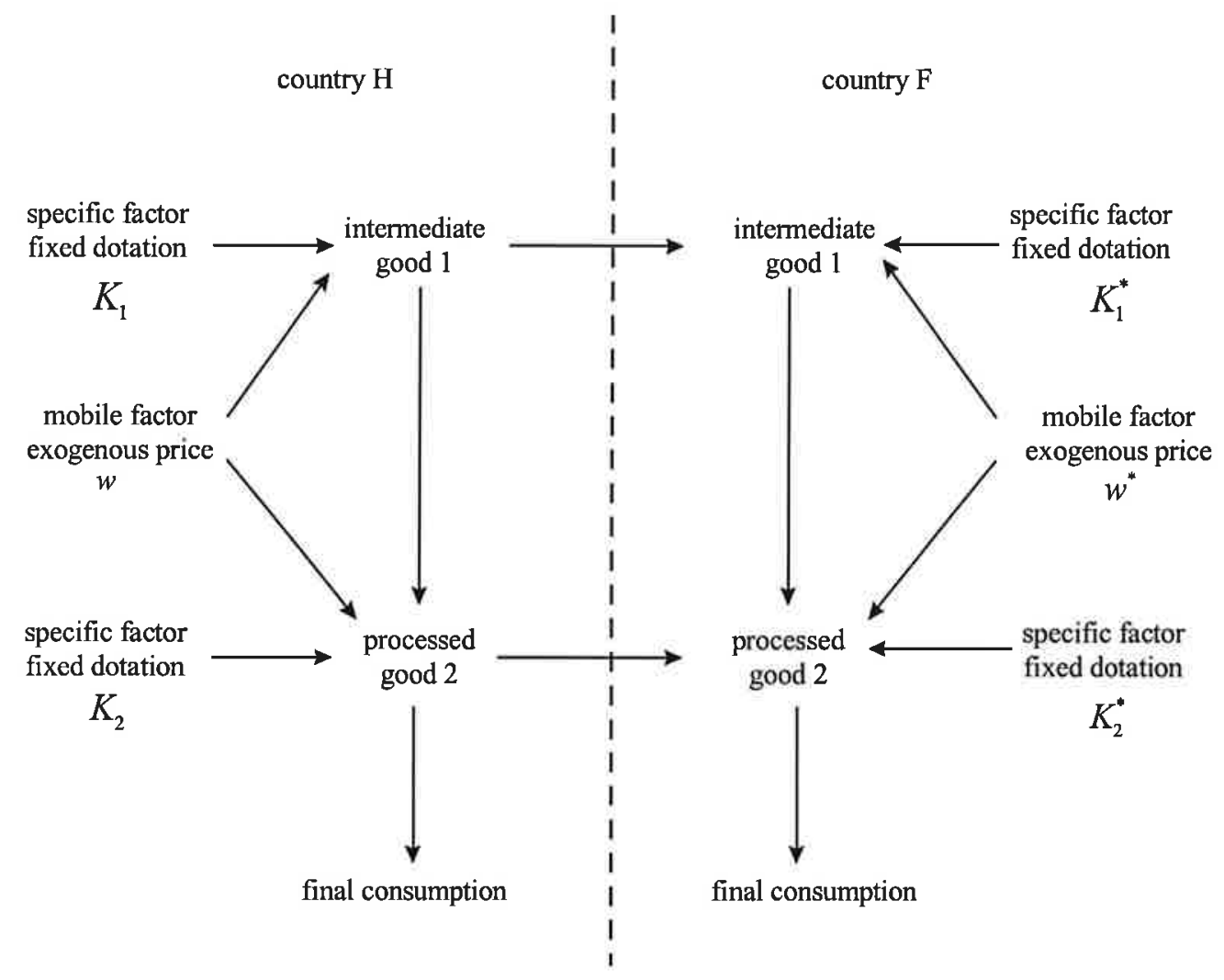

Let us consider the home country. Each industry may be represented by a well-behaved restricted profit function, $\pi^{1}\left(p s_{1}, w, K_{1}\right)$ for the bulk commodity industry and $\pi^{2}\left(p s_{2}, p d_{1}, w, K_{2}\right)$ for the HVP industry. From Hotelling's lemma, the supply function for the bulk commodity 1 , the supply function for the final good 2 and the derived demand function for the raw input 1 are given by (omitting the arguments $w, K_{1}$ and $K_{2}$ ):

(1) $S_{1}\left(p s_{1}\right) \equiv \pi_{1}^{1}\left(p s_{1}\right)$

(2) $S_{2}\left(p s_{2}, p d_{1}\right) \equiv \pi_{2}^{2}\left(p s_{2}, p d_{1}\right)$,

(3) $D_{1}\left(p s_{2}, p d_{1}\right) \equiv-\pi_{1}^{2}\left(p s_{2}, p d_{1}\right)$,

where $\pi_{i}^{j}$ denotes the partial derivative of the profit function in sector $j$ with respect to the price of netput $i$.

The export supply function for each good is then defined by: 
(4) $X_{1}\left(p s_{1}, p s_{2}, p d_{1}\right) \equiv S_{1}\left(p s_{1}\right)-D_{1}\left(p s_{2}, p d_{1}\right)$,

(5) $X_{2}\left(p s_{2}, p d_{1}, p d_{2}\right) \equiv S_{2}\left(p s_{2}, p d_{1}\right)-D_{2}\left(p d_{2}\right)$,

where $D_{2}\left(p d_{2}\right)$ is the home country's final demand function for good 2 . We assume there is no final consumption of good 1.

The market clearing conditions require world trade in each commodity to sum to zero, i.e.,

(6) $X_{1}\left(p s_{1}, p s_{2}, p d_{1}\right)+X_{1}^{*}\left(p_{1}^{*}, p_{2}^{*}\right)=0$,

(7) $X_{2}\left(p s_{2}, p d_{1}, p d_{2}\right)+X_{2}^{*}\left(p_{2}^{*}, p_{1}^{*}\right)=0$.

The welfare function in the home country is defined as the sum of the bulk commodity industry surplus $\left(\Psi_{1}\right)$, the HVP industry surplus $\left(\Psi_{2}\right)$ and the consumer surplus $\left(\Psi_{c}\right)$, less the taxpayer cost of the policy $\left(\Psi_{t}\right)$ :

(8) $W=\Psi_{1}+\Psi_{2}+\Psi_{c}-\Psi_{t}$,

with

(9) $\Psi_{1} \equiv \pi^{1}\left(p s_{1}\right)$,

(10) $\Psi_{2} \equiv \pi^{2}\left(p s_{2}, p d_{1}\right)$,

(11) $\Psi_{c} \equiv \int_{0}^{D_{2}}\left(D_{2}\right)^{-1}(t) d t-p d_{2} D_{2}$,

(12a) $\Psi_{t} \equiv(1+\delta) \cdot\left[\left(p s_{1}-p_{1}^{*}\right) \cdot X_{1}+\left(p s_{2}-p_{2}^{*}\right) \cdot X_{2}+\left(p s_{1}-p d_{1}\right) \cdot D_{1}+\left(p s_{2}-p d_{2}\right) \cdot D_{2}\right]$,

where $\delta$ is the marginal excess burden of taxation, and where the four right-hand terms of (12a) represent the taxpayer cost of export subsidies for good 1, export subsidies for good 2, domestic derived consumption subsidies for good 1 and domestic final consumption subsidies for good 2, respectively. Each "subsidy" can be a "tax" since we do not rule out a priori a domestic supply price lower than the world price (i.e., $p s_{i}<p_{i}^{*}$ ) and a domestic supply price lower than the domestic consumption price (i.e., $p s_{i}<p d_{i}$ ). 
Clearly, more than one set of price instruments would achieve the same partial equilibrium outcome (Dixit and Norman, Moschini and Sckokai). Using export supply function definitions (4) and (5), one easily shows that $\Psi_{t}$ could equivalently be defined as a combination of export and output subsidies/taxes (equation (12b)) or as a combination of output and consumption subsidies/taxes (equation (12c)).

(12b) $\Psi_{t} \equiv(1+\delta) \cdot\left[\left(p d_{1}-p_{1}^{*}\right) \cdot X_{1}+\left(p d_{2}-p_{2}^{*}\right) \cdot X_{2}+\left(p s_{1}-p d_{1}\right) \cdot S_{1}+\left(p s_{2}-p d_{2}\right) \cdot S_{2}\right]$,

$(12 c) \Psi_{t} \equiv(1+\delta) \cdot\left[\left(p s_{1}-p_{1}^{*}\right) \cdot S_{1}+\left(p s_{2}-p_{2}^{*}\right) \cdot S_{2}+\left(p_{1}^{*}-p d_{1}\right) \cdot D_{1}+\left(p_{2}^{\prime \prime}-p d_{2}\right) \cdot D_{2}\right]$

\section{Optimization program}

The home country's government objective is the maximization of domestic welfare, subject to the constraints that total rent to farmers and agribusiness firms must be at least as large as given income targets $\bar{\pi}^{1}$ and $\bar{\pi}^{2}$, respectively. In terms of the notation introduced above, the lagrangean for this maximization problem may be written as:

(13) $L\left(p s_{1}, p d_{1}, p s_{2}, p d_{2}\right) \equiv W+\lambda\left(\pi^{1}-\bar{\pi}^{1}\right)+\mu\left(\pi^{2}-\bar{\pi}^{2}\right)$,

where $\lambda$ (respectively, $\mu$ ) is the Lagrange multiplier associated with the minimal bulk commodity (respectively, processed commodity) industry income constraint. When the two Lagrange multipliers in (13) equal zero, the maximization program reduces to an unconstrained optimization problem, i.e., to the characterization of the first best optimal price policy. If the objective of the government is to transfer income to farmers only, the second Lagrange multiplier in (13) is set to zero. Differentiating (13) gives:

$$
\begin{aligned}
d L= & (1+\delta) \cdot\left[X_{1} \cdot d p_{1}^{*}+X_{2} \cdot d p_{2}^{*}-\left(p s_{1}-p_{1}^{*}\right) \cdot d X_{1}+\left(p s_{2}-p_{2}^{*}\right) \cdot d X_{2}-\left(p s_{1}-p d_{1}\right) \cdot d D_{1}\right. \\
& \left.-\left(p s_{2}-p d_{2}\right) \cdot d D_{2}\right]-\delta \cdot\left[S_{1} \cdot d p s_{1}+S_{2} \cdot d p s_{2}-D_{1} \cdot d p d_{1}-D_{2} \cdot d p d_{2}\right] \\
& +\lambda \cdot S_{1} \cdot d p s_{1}+\mu \cdot\left(S_{2} \cdot d p s_{2}-D_{1} \cdot d p d_{1}\right) .
\end{aligned}
$$


The two world prices, $p_{1}^{*}$ and $p_{2}^{*}$, solve the two world market equilibrium conditions (6) and (7). Differentiating (6) and (7) using (4) and (5) gives:

(15) $S_{11} \cdot d p s_{1}-D_{11} \cdot d p d_{1}-D_{12} \cdot d p s_{2}+X_{11}^{*} \cdot d p_{1}^{*}+X_{12}^{*} \cdot d p_{2}^{*}=0$

(16) $S_{21} \cdot d p d_{1}+S_{22} \cdot d p s_{2}-D_{22} \cdot d p d_{2}+X_{21}^{*} \cdot d p_{1}^{*}+X_{22}^{*} \cdot d p_{2}^{*}=0$

where $S_{11}=\pi_{11}^{1}>0, \quad S_{22}=\pi_{22}^{2}>0, \quad D_{11}=-\pi_{11}^{2}<0, \quad S_{21}=\pi_{21}^{2}=\pi_{12}^{2}=-D_{12}<0 \quad$ under the assumption that good 1 is a normal input in production of good $2, X_{11}^{*}=S_{11}^{*}-D_{11}^{*}>0$, $X_{12}^{*}=-D_{12}^{*}=S_{21}^{*}=X_{21}^{*}<0$ and $X_{22}^{*}=S_{22}^{*}-D_{22}^{*}>0$.

Inverting (15) and (16) yields:

$$
\left[\begin{array}{l}
d p_{1}^{*} \\
d p_{2}^{*}
\end{array}\right]=\left(\frac{1}{\Delta^{*}}\right) \cdot\left[\begin{array}{cccc}
-S_{11} \cdot X_{22}^{*} & D_{11} X_{22}^{*}+S_{21} X_{12}^{*} & D_{12} X_{22}^{*}+S_{22} X_{12}^{*} & -D_{22} \cdot X_{12}^{*} \\
S_{11} \cdot X_{21}^{*} & -D_{11} X_{21}^{*}-S_{21} X_{11}^{*} & -D_{12} X_{21}^{*}-S_{22} X_{11}^{*} & D_{22} X_{11}^{*}
\end{array}\right] \cdot\left[\begin{array}{l}
d p s_{1} \\
d p d_{1} \\
d p s_{2} \\
d p d_{2}
\end{array}\right]
$$

where $\Delta^{*}=X_{11}^{*} \cdot X_{22}^{*}-X_{12}^{*} \cdot X_{21}^{*}>0 .^{3}$

Differentiating (4) and (5) and substituting corresponding expressions as well as (17) into (14), we obtain an expression of $d L$ in terms of the variations of the four choice variables, i.e., $d p s_{1}, d p d_{1}, d p s_{2}$ and $d p d_{2}$ :

$$
\begin{aligned}
d L= & {\left[(1+\delta) \cdot\left(\frac{-S_{11} X_{22}^{*}}{\Delta^{*}} \cdot X_{1}+\frac{S_{11} X_{21}^{*}}{\Delta^{*}} \cdot X_{2}-\left(p s_{1}-p_{1}^{*}\right) \cdot S_{11}\right)+(\lambda-\delta) \cdot S_{1}\right] \cdot d p s_{1} } \\
& +\left[(1+\delta) \cdot\left(\frac{D_{11} X_{22}^{*}+S_{21} X_{12}^{*}}{\Delta^{*}} \cdot X_{1}-\frac{D_{11} X_{21}^{*}+S_{21} X_{11}^{*}}{\Delta^{*}} \cdot X_{2}+\left(p d_{1}-p_{1}^{*}\right) \cdot D_{11}-\left(p s_{2}-p_{2}^{*}\right) \cdot S_{21}\right)\right. \\
& \left.-(\mu-\delta) \cdot D_{1}\right] \cdot d p d_{1} \\
& +\left[(1+\delta) \cdot\left(\frac{D_{12} X_{22}^{*}+S_{22} X_{12}^{*}}{\Delta^{*}} \cdot X_{1}-\frac{D_{12} X_{21}^{*}+S_{22} X_{11}^{*}}{\Delta^{*}} \cdot X_{2}+\left(p d_{1}-p_{1}^{*}\right) \cdot D_{12}-\left(p s_{2}-p_{2}^{*}\right) \cdot S_{22}\right)\right. \\
& \left.+(\mu-\delta) \cdot S_{2}\right] \cdot d p s_{2} \\
& +\left[(1+\delta) \cdot\left(\frac{-D_{22} X_{12}^{*}}{\Delta^{*}} \cdot X_{1}+\frac{D_{22} X_{11}^{*}}{\Delta^{*}} \cdot X_{2}+\left(p d_{2}-p_{2}^{*}\right) \cdot D_{22}\right)+\delta \cdot D_{2}\right] \cdot d p d_{2} \cdot
\end{aligned}
$$


Optimal intervention is obtained by equating to zero the partial derivatives of the lagrangean with respect to the four domestic prices, i.e., by equating to zero each term in brackets in equation (18). Two cases have to be considered depending on the determinant $\Delta=D_{12} \cdot S_{21}-D_{11} \cdot S_{22}$ be strictly positive or equal to zero. ${ }^{4}$ We first present the results in the case where $\Delta>0$.

\section{Efficient price policy for the two country, two good economy (case where $\Delta>0$ )}

\section{Optimal price wedges}

When the determinant $\Delta$ is strictly positive, the four first-order conditions may be written in terms of price differences $p s_{1}-p_{1}^{*}, p s_{1}-p d_{1}, p s_{2}-p_{2}^{*}$ and $p s_{2}-p d_{2}$ :

(19a) $p s_{1}-p_{1}^{*}=\frac{-X_{1} X_{22}^{*}+X_{2} X_{21}^{*}}{\Delta^{*}}+\frac{\lambda}{1+\delta} \cdot \frac{S_{1}}{S_{11}}-\frac{\delta}{1+\delta} \cdot \frac{S_{1}}{S_{11}}$,

(19b) $p s_{1}-p d_{1}=\frac{\lambda}{1+\delta} \cdot \frac{S_{1}}{S_{11}}+\frac{\mu}{1+\delta} \cdot \frac{D_{1} S_{22}-S_{2} D_{12}}{\Delta}-\left(\frac{\delta}{1+\delta} \cdot \frac{S_{1}}{S_{11}}+\frac{\delta}{1+\delta} \cdot \frac{D_{1} S_{22}-S_{2} D_{12}}{\Delta}\right)$,

(20a) $p s_{2}-p_{2}^{*}=\frac{X_{1} X_{12}^{*}-X_{2} X_{11}^{*}}{\Delta^{*}}+\frac{\mu}{1+\delta} \cdot \frac{D_{1} S_{21}-S_{2} D_{11}}{\Delta}-\frac{\delta}{1+\delta} \cdot \frac{D_{1} S_{21}-S_{2} D_{11}}{\Delta}$,

(20b) $p s_{2}-p d_{2}=\frac{\mu}{1+\delta} \cdot \frac{D_{1} S_{21}-S_{2} D_{11}}{\Delta}+\left(\frac{\delta}{1+\delta} \cdot \frac{D_{2}}{D_{22}}-\frac{\delta}{1+\delta} \cdot \frac{D_{1} S_{21}-S_{2} D_{11}}{\Delta}\right)$.

By difference, we immediately obtain optimal expressions for $p d_{1}-p_{1}^{*}$ and $p d_{2}-p_{2}^{*}$ :

(19c) $p d_{1}-p_{1}^{*}=\frac{-X_{1} X_{22}^{*}+X_{2} X_{21}^{*}}{\Delta^{*}}-\frac{\mu}{1+\delta} \cdot \frac{D_{1} S_{22}-S_{2} D_{12}}{\Delta}+\frac{\delta}{1+\delta} \cdot \frac{D_{1} S_{22}-S_{2} D_{12}}{\Delta}$,

(20c) $p d_{2}-p_{2}^{*}=\frac{X_{1} X_{12}^{*}-X_{2} X_{11}^{*}}{\Delta^{*}}-\frac{\delta}{1+\delta} \cdot \frac{D_{2}}{D_{22}}$.

\section{Interpretation with the targeting principle}

In a general way, the government chooses four prices, e.g., the supply price of the agricultural product 1 , the supply price of the processed good 2 , the domestic derived demand price of the agricultural product 1 and the domestic final consumption price of the processed good 2 . 
Clearly, more than one set of subsidy and/or tax instruments can be used to achieve the same optimal equilibrium outcome. We expose here the policy consistent with the targeting principle (Bhagwati). According to this principle, "when distortions have to be introduced in the economy, because the values of certain variables have to be constrained, the optimal (or least-cost) method of doing this is to choose that policy intervention that creates the distortion affecting directly the constrained variable" (p. 71).

\section{Improvement of the terms of trade}

For each good, the terms of trade distortion calls for a negative price wedge between the two domestic prices and the corresponding export price, i.e., $\left(-X_{1} X_{22}^{*}+X_{2} X_{21}^{*}\right) / \Delta^{*}<0$ on market 1 and $\left(X_{1} X_{12}^{*}-X_{2} X_{11}^{*}\right) / \Delta^{*}<0$ on market $2^{5}$. According to the targeting principle, these negative price wedges should be achieved by export taxes to improve the international terms of trade by exploiting the large country market power. In the particular case where $\lambda=\mu=\delta=0$, equations (19a) and (20a) (or, equivalently, (19c) and (20c)) reduce to:

(21) $\left[p s_{1}-p_{1}^{*}, p s_{2}-p_{2}^{*}\right]=\left[p d_{1}-p_{1}^{*}, p d_{2}-p_{2}^{*}\right]=\left[-X_{1}^{*},-X_{2}^{*}\right] \cdot\left[\begin{array}{cc}X_{11}^{*} & X_{12}^{*} \\ X_{21}^{*} & X_{22}^{*}\end{array}\right]^{-1}$.

This formula generalizes the two country, one good partial equilibrium model result that the optimal export tax equals the inverse elasticity of the foreign offer curve (Dixit and Norman, Feenstra).

\section{Revenue constraint towards producers of good 1}

The least-cost policy to achieve the predetermined bulk commodity producer welfare requires a positive price wedge between the bulk commodity supply price and the two demand prices (i.e. the domestic demand and the export prices) of that good, $\lambda . S_{1} /\left[S_{11}(1+\delta)\right]>0$ (equations (19a) and (19b)). The targeting principle calls for a production subsidy on good 1 in order to satisfy the bulk commodity producer income target. 


\section{Revenue constraint towards producers of good 2}

In order to increase the HVP producer income, the government can raise the supply price of good 2 and/or diminish the domestic derived demand price of good 1 . One verifies then that optimality requires two additional price wedges, $p_{1}-p d_{1}=\mu .\left(D_{1} S_{22}-S_{2} D_{12}\right) /[(1+\delta) . \Delta]$ in equations (19b) and (19c) as well as $p s_{2}-p_{2}=\mu .\left(D_{1} S_{21}-S_{2} D_{11}\right) /[(1+\delta) . \Delta]$ in equations (20a) and (20b). ${ }^{6}$ These two supplementary price wedges may be written as:

(21) $\left[p s_{2}-p_{2}, p d_{1}-p_{1}\right]=\mu \cdot\left[S_{2},-D_{1}\right] \cdot\left[\begin{array}{cc}S_{22} & -D_{12} \\ S_{21} & -D_{11}\end{array}\right]^{-1}=\mu \cdot\left[\pi_{2}^{2}, \pi_{1}^{2}\right] \cdot\left[\begin{array}{ll}\pi_{22}^{2} & \pi_{12}^{2} \\ \pi_{21}^{2} & \pi_{11}^{2}\end{array}\right]^{-1}$.

At the point of optimal intervention, we then have: ${ }^{7}$

(22) $\left(p s_{2}-p_{2}\right) \cdot S_{2}+\left(p_{1}-p d_{1}\right) \cdot D_{1}>0$.

Equation (22) shows that price policy expenditure implemented to achieve the HVP producer income target must be positive at the optimum. This inequality rules out the possibility of taxing both output of good 2 and domestic consumption of good 1 , or having no domestic price policy in sector 2. One also notes that a joint intervention on $p s_{2}$ and $p d_{1}$ is superior to a univariate intervention on $p s_{2}$ only, or $p d_{1}$ only.

After some tedious manipulation and simplification, the price wedge $p s_{2}-p_{2}$ may equivalently be written in elasticity form as: ${ }^{8}$

$$
\frac{p s_{2}-p_{2}}{p s_{2}}=\mu \cdot \frac{\partial \log \hat{S}_{2}\left(p s_{2}, w, D_{1}, K_{2}\right) / \partial \log K_{2}}{\partial \log \hat{S}_{2}\left(p s_{2}, w, D_{1}, K_{2}\right) / \partial \log p s_{2}}=\mu \cdot \frac{\sigma_{1 K}-\sigma_{K K}}{\sigma_{11} \sigma_{K K}-\left(\sigma_{1 K}\right)^{2}}
$$

where $\hat{S}_{2}\left(p s_{2}, w, D_{1}, K_{2}\right)$ denotes the constrained supply function of good 2 for a fixed level of input 1 (and a fixed level of specific input $K_{2}$ ), $\sigma_{11}$ is the unconstrained own elasticity of substitution for input $D_{1}, \sigma_{K K}$ is the unconstrained own elasticity of substitution for input $K_{2}$, and $\sigma_{1 K}$ is the unconstrained Hicks-Allen partial elasticity of substitution between $D_{1}$ and $K_{2}$. 
The denominator in (23) is positive by convexity in prices of the unit unconstrained cost function. The numerator in (23) is positive as long as the specific factor $K_{2}$ is "normal" in the production of good 2, i.e., as $\operatorname{long}$ as $\partial \log \hat{S}_{2} / \partial \log K_{2}>0 .^{9}$ In that case, the redistribution objective to HVP producers requires a positive price wedge between the supply price of good 2 and the corresponding fictitious price (i.e., $p s_{2}-p_{2}>0$, or equivalently $D_{1} S_{21}-S_{2} D_{11}>0$ ). The targeting principle thus calls for a production subsidy on good 2 .

Similarly, the second price wedge $p d_{1}-p_{1}$ may be written in elasticity form as: ${ }^{10}$

(24) $\frac{p d_{1}-p_{1}}{p d_{1}}=\mu \cdot \frac{-\partial \log \hat{D}_{1}\left(p d_{1}, w, S_{2}, K_{2}\right) / \partial \log K_{2}}{-\partial \log \hat{D}_{1}\left(p d_{1}, w, S_{2}, K_{2}\right) / \partial \log p d_{1}}=\mu \cdot \frac{\sigma_{1 K}}{\sigma_{11} \sigma_{K K}-\left(\sigma_{1 K}\right)^{2}}$

where $\hat{D}_{1}\left(p d_{1}, w, S_{2}, K_{2}\right)$ denotes the constrained derived demand of good 1 for a fixed level of output 2 and a fixed level of specific input $K_{2}$.

The numerator in (24) is negative (respectively positive) when $D_{1}$ and $K_{2}$ are long-run hicksian complements (respectively substitutes). According to the targeting principle, a consumption subsidy on good 1 should be used when $D_{1}$ and $K_{2}$ are long-run hicksian complements $\left(D_{1} S_{22}-S_{2} D_{12}>0\right)$ while a consumption tax should be used when these inputs are long-run hicksian substitutes $\left(D_{1} S_{22}-S_{2} D_{12}<0\right)$. Let us consider the tax case more closely. The consumption tax on good 1 tends to raise $p d_{1}$ and hence to diminish $D_{1}$, other things equal. The substitution effect between $D_{1}$ and $K_{2}$ causes quasi-rents to the specific factor $K_{2}$ to rise. However, the tax also causes the supply of good 2 to decrease and this contraction effect contributes to a decrease in quasi-rents to the specific factor $K_{2}$. In the case where a production subsidy on good 2 is used jointly with a consumption tax on good 1 , the former raises the HVP supply by an expansion effect which compensates the tax-induced decrease in good 2 supply. The optimal outcome thus corresponds to a consumption tax on 
good 1 (in the sense of $p d_{1}>p_{1}$ ) and a production subsidy on good 2 (in the sense of $\left.p s_{2}>p_{2}\right)$.

\section{Correction of the fiscal distortion}

The presence of distortionary taxation entails additional price wedges in the six equations (19a) to (20c). Insights are gained by considering the unconstrained optimal policy $(\lambda=\mu=0)$ in the small country case where $p_{1}^{*}$ and $p_{2}^{*}$ are fixed. In that case, the optimal price wedges reduce to:

(25a) $p s_{1}-p_{1}^{*}=-T . S_{1} / S_{11}$,

(25c) $p_{1}^{*}-p d_{1}=-T \cdot\left(D_{1} S_{22}-S_{2} D_{12}\right) / \Delta$

(26a) $p s_{2}-p_{2}^{*}=-T \cdot\left(D_{1} S_{21}-S_{2} D_{11}\right) / \Delta$,

(26c) $p_{2}^{*}-p d_{2}=T \cdot D_{2} / D_{22}$,

Where $T=\delta /(1+\delta)$.

These expressions show that the unconstrained optimal policy requires a simultaneous intervention on both the two supply prices and the two consumption prices. Two price wedges, $p s_{1}-p_{1}^{*}$ and $p_{2}^{*}-p d_{2}$, are unambiguously negative calling for a production tax on good 1 and a consumption tax on good 2, respectively. The two other price wedges are theoretically indeterminate in sign. Under the rather unrestrictive assumption that $K_{2}$ is a normal input, the price wedge $p s_{2}-p_{2}^{*}$ is negative calling for a production tax on good 2 . The last price wedge, $p_{1}^{*}-p d_{1}$, is negative (respectively positive) when $D_{1}$ and $K_{2}$ are long-run hicksian complements (respectively substitutes). Nevertheless, even in the case where the optimal policy corresponds to a consumption subsidy on good 1, i.e., when $D_{1}$ and $K_{2}$ are long-run hicksian substitutes, one can show that the following inequality holds:

(27) $\left(p s_{2}-p_{2}^{*}\right) \cdot S_{2}+\left(p_{1}^{*}-p d_{1}\right) \cdot D_{1}<0$. 
Inequality (27) states that tax revenue in the HVP industry must be positive at the optimum. In other words, the effect of the consumption subsidy on good 1 (which is implemented when $D_{1}$ and $K_{2}$ are long-run hicksian substitutes) is more than offset by the effect of the production tax on good 2 so that there is a positive tax rate in the HVP industry. In all cases, there is a net budgetary transfer from producers of good 1, producers of good 2 and final consumers of good 2 towards taxpayers (other things equal). In other words, there is then a net budgetary transfer from producers of both goods and final consumers towards taxpayers. At this stage, the following remark is in order. The parameter $\delta$ (or, equivalently, $T$ ) reflects the deadweight cost of raising taxes in the economy when lump-sum taxation is not available. Following Neary, we assume that there is some other component of public spending which must always be financed and that any change in subsidy/tax payments in the considered industry is accompanied by a change in tax revenue in the rest of the economy. It follows that the value of $\delta$ is the same when the optimal policy in the considered industry corresponds to budgetary receipts or expenditure.

\section{Summary}

The decomposition of the optimal price wedges consistent with the targeting principle is summarized in the following table.

\begin{tabular}{|c|c|c|c|c|c|c|c|}
\hline \multirow{2}{*}{$\begin{array}{l}\text { Optimal } \\
\text { price } \\
\text { wedges }\end{array}$} & \multirow{2}{*}{$\begin{array}{l}\text { terms } \\
\text { of } \\
\text { trade }\end{array}$} & \multicolumn{2}{|c|}{ producers of good 1} & \multicolumn{3}{|c|}{ producers of good 2} & \multirow{2}{*}{$\begin{array}{c}\text { final } \\
\text { demand }\end{array}$} \\
\hline & & redistribution & taxation & & redistribution & taxation & \\
\hline$p s_{1}-\dot{p_{1}}$ & - & + & - & & & & \\
\hline$p s_{1}-p d_{1}$ & & + & - & $\begin{array}{l}D_{1} \text { and } K_{2} \text { substitutes } \\
D_{1} \text { and } K_{2} \\
\text { complements }\end{array}$ & $\bar{r}$ & $\begin{array}{l}+ \\
-\end{array}$ & \\
\hline$p d_{1}-p_{1}^{*}$ & - & & & $\begin{array}{c}D_{1} \text { and } K_{2} \text { substitutes } \\
D_{1} \text { and } K_{2} \\
\text { complements }\end{array}$ & $\begin{array}{l}+ \\
-\end{array}$ & $\dot{+}$ & \\
\hline$p s_{2}-p_{2}^{*}$ & - & & & $K_{2}$ normal input & + & - & \\
\hline$p s_{2}-p d_{2}$ & & & & $K_{2}$ normal input & + & - & - \\
\hline$p d_{2}-p_{2}^{*}$ & - & & & & & & + \\
\hline
\end{tabular}




\section{Implementation of the optimal price policy}

The targeting principle provides a set of simple and intuitive rules for policy intervention However, a same policy instrument is used, in practice, to correct different distortions with opposing effects and hence it is impossible, in general, to define a neat targeting policy, as summarized in the preceding table. A case-by-case approach must therefore be adopted by simultaneously considering all existing distortions (i.e., small or large country, $\lambda=0$ or $\lambda>0, \mu=0$ or $\mu>0$, and $\delta=0$ or $\delta>0$ ) and available instruments. We briefly consider here the general case where $\lambda>0, \mu>0$ and $\delta>0$, assuming that the government uses export subsidies and/or taxes as well as production subsidies and/or taxes. As a result, we use expression (12b) to characterize the optimal policy.

From (20c), one verifies that the terms of trade distortion calls for an export tax on good 2 while the fiscal distortion calls for an export subsidy on good 2. Accordingly, exports of good

2 can be subsidized or taxed (in the sense that $\left(p d_{2}-p_{2}^{*}\right) \cdot X_{2}>0$ or $<0$ ). This result is structurally the same as the one derived by Alston et al. (1993) in the two country, one good model. In particular, equation (20c) shows that this result does not directly depend on the size of the transfer to both farmers and agribusiness firms. In addition, in our two-markets framework, cross effects between good 1 and good 2 are taken into account to determine the optimal "export tax" (corresponding to the first right-hand side term of (20c)) implemented to exploit the home country market power on the export market of good 2 .

From (19c), one then notes that the conditions under which exports of good 1 are subsidized (respectively taxed) when combined with production subsidies/taxes are more complicated. These conditions mainly depend on the size of the transfer to HVP producers (via the value of the Lagrange multiplier $\mu$ ) and on the substitution-complementarity relationship between $D_{1}$ 
and $K_{2}$ in the home country. Let us first assume that $\mu<\delta$ (i.e., that the transfer to agribusiness firms is smaller than the taxation of this sector, or, equivalently, that the net policy effect is a taxation of this sector). In that case, exports of good 1 are taxed (in the sense that $\left.\left(p d_{1}-p_{1}^{*}\right) X_{1}<0\right)$ when $D_{1}$ and $K_{2}$ are long-run hicksian substitutes and they are taxed or subsidized (in the sense that $\left(p d_{1}-p_{1}^{*}\right) X_{1}<0$ or $\left.>0\right)$ when $D_{1}$ and $K_{2}$ are long-run hicksian complements depending on the relative magnitudes of $-\left(X_{1} X_{22}^{*}-X_{2} X_{21}^{*}\right) / \Delta<0$ and $-(\mu-\delta) .\left(D_{1} S_{22}-S_{2} D_{12}\right) /(1+\delta) . \Delta>0$. Let us now assume that $\mu>\delta$ (i.e. that there exists a net redistribution towards processors). In that case, exports of good 1 are taxed when $D_{1}$ and $K_{2}$ are long-run hicksian complements and they are taxed or subsidized when these inputs are substitutes.

The latter results are sharpened when applied to the small open economy case. As long as $\mu$ is lower than $\delta$, domestic consumption of good 1 is subsidized (respectively taxed) when $D_{1}$ and $K_{2}$ are long-run hicksian substitutes (respectively complements). When $\mu$ is greater than $\delta$, the rule is inverted and domestic consumption of good 1 is subsidized (respectively taxed) when $D_{1}$ and $K_{2}$ are long-run hicksian complements (respectively substitutes).

Back to the large country case, the special case where there is no excess burden of taxation $(\delta=0)$ is interesting. From (20c), one verifies that the optimal policy necessarily corresponds to an export tax on good 2 (in the sense of $\left.\left(p d_{2}-p_{2}^{*}\right) \cdot X_{2}<0\right)$. The price wedge $p d_{1}-p_{1}^{*}$ is unambiguously negative when $D_{1}$ and $K_{2}$ are long-run hicksian complements, but it is indeterminate in sign when they are substitutes. In the first case, the government uses an export tax on good 1 (in the sense that $\left.\left(p d_{1}-p_{1}^{*}\right) . X_{1}<0\right)$. In the second case, the terms of trade distortion calls for an export tax and the redistribution distortion towards HVP producers 
calls for an export subsidy. If the latter outweighs the effects of the terms of trade distortion, the government uses an export subsidy on good 1 (in the sense of $\left.\left(p d_{1}-p_{1}^{*}\right) \cdot X_{1}>0\right)$.

This result shows that even in the absence of distortionary taxation, it can be optimal for the government to subsidize exports of good 1 with respect to domestic consumption when the policy objective is to transfer income to both farmers and agribusiness firms. Furthermore, in the small country case, and when $D_{1}$ and $K_{2}$ are long-run hicksian substitutes, the optimal outcome necessarily corresponds to an export subsidy on good 1 relative to domestic consumption. These findings are in contrast with those derived in the two country, one good partial equilibrium model where exports are always taxed relative to domestic consumption when there is no excess burden of taxation.

Efficient price policy for the two country, two good economy (Leontief case, $\Delta=0$ )

We briefly consider the special case where the technology in sector 2 is Leontief with respect to good 1. The fixed technical coefficient is denoted $a$ and the following relationships are verified: $S_{2}=a \cdot D_{1}, S_{21}=a \cdot D_{11}$ and $S_{22}=a \cdot D_{12}$. Accordingly $\Delta=0$, and the optimal price policy reduces to equations $(19 a),(19 b)$ and :

(21c) $\left(p s_{2}-p d_{2}\right)+\frac{1}{a} \cdot\left(p s_{1}-p d_{1}\right)=\frac{1}{a} \cdot \frac{\lambda-\delta}{1+\delta} \cdot \frac{S_{1}}{S_{11}}+\frac{\mu-\delta}{1+\delta} \cdot \frac{S_{2}}{S_{22}}+\frac{\delta}{1+\delta} \cdot \frac{D_{2}}{D_{22}}$, with $\frac{1}{a}=\frac{D_{12}}{S_{22}}$.

Equations (19a) and (19b) are structurally the same as those derived in the general case with $\Delta>0$. Equation (21c) shows that there now exists a linear relationship between the two price wedges $p s_{2}-p d_{2}$ and $p s_{1}-p d_{1}$. It follows that the optimal outcome can be achieved by choosing a) the supply price of good $1 p s_{1}$ which satisfies (21a), b) the domestic demand price of good $2 p d_{2}$ which satisfies (21b), and c) the price difference $p s_{2}-p d_{1} / a$ which satisfies (21c). This last result follows directly from the Leontief assumption which implies that equilibrium quantities no more depend on price levels $p s_{2}$ and $p d_{1}$, but only on price 
wedge $p s_{2}-p d_{1} / a .^{11}$ The supply function of good 2 may then be written as $S_{2}\left(p s_{2}-p d_{1} / a, w, K_{2}\right)$. Similarly, the derived demand function for good 1 may be written as $D_{1}\left(p s_{2}-p d_{1} / a, w, K_{2}\right)$. It results that an optimal solution can be achieved by acting on $p s_{2}$ only, on $p d_{1}$ only, or simultaneously on $p s_{2}$ and $p d_{1}$, under the condition that they yield the same optimal price wedge $p s_{2}-p d_{1} / a$. In other words, our earlier analysis applies except that there now exits an infinite set of price couples $\left(p s_{2}, p d_{1}\right)$ which can be used to achieve the optimal outcome.

\section{Policy implications and concluding comments}

In this paper, the targeting principle is used to explain how the government should intervene with price instruments in two vertically related markets in order to correct the distortions arising from i) the possibility to improve the terms of trade, ii) the redistribution constraint(s) towards agricultural producers and/or processors, and iii) the distortionary taxation. However, it is generally impossible to identify a neat targeting policy since the various distortions have, more often, opposing effects in optimal price wedge equations. With respect to the traditional one good setting, there is in addition a market linkage between good 1 and 2 which also affects the targeting principle and contributes to the ambiguity. The discussion then shows conditions under which export subsidies on both goods may be optimal when combined with production subsidies and/or taxes. In particular, exports of good 1 can now be subsidized relative to domestic consumers even if the marginal excess burden of taxation equals zero. This result is in contrast with the one derived in the two country, one good model where exports of the agricultural good are always taxed relative to domestic consumption when taxation is not distortionary. More generally, the conditions under which exports of good 1 are subsidized or taxed relative to domestic consumers mainly depend on the marginal excess burden of taxation, the size of the desired transfer to agribusiness firms and direct and cross 
behavioral parameters, at home and abroad. The home country substitution-complementarity relationship between input 1 and output 2 in production of good 2 is a key element to be considered in that respect.

At this stage, it is interesting to note that our analysis framework can readily be modified to be applied to the level of input suppliers and agricultural good producers by considering that good 1 corresponds to an intermediate input, fertilizers for example, used in production of the agricultural product. In that case, one could show that the optimal policy requires a simultaneous intervention on both the input and agricultural markets.

Our analysis incorporates certain simplifying assumptions and numerous issues remain for further activities within the research line initiated here. To begin with the choice of policies, it would be important to add supplementary instruments to the government's toolbox, in particular output quotas, supply control policies through input retirement programs, and decoupled payments. Our results are subject to the limitation that the marginal deadweight loss of taxation is assumed constant. As noted by Moschini and Sckokai, this assumption is defensible if income support requires only a small fraction of total tax revenue. ${ }^{12}$ Finally, we believe that it would be important to consider the issue of market structure in the processing sector. Our analysis framework could be used to determine the full set of optimal taxes and subsidies imposed on an intermediate good or a final good in vertically related markets characterized by imperfect market structures. Lanclos and Hertel, and Lanclos et al. have highlighted the importance of trade policies directed towards intermediate inputs on equilibrium in the differentiated final products sector. But, to our knowledge, there is no study of this issue within the framework of efficient redistribution.

\section{References}


Alston, J. M., C. A. Carter, and V. H. Smith. "Rationalizing Agricultural Export Subsidies.", Amer. J. Agr. Econ. 75 (November 1993):1000-1009.

Alston, J. M., C. A. Carter, and M. K. Wohlgenant. "Who Determines Farm Programs? Agribusiness and the Making of Farm Policy.", IATRC Working Paper 89-1 (January 1989).

Alston, J. M., and B. H. Hurd. "Some Neglected Social Costs of Government Spending in Farm Programs." Amer. J. Agr. Econ. 72 (February 1990):149-56.

Bhagwati, J. N. "The Generalized Theory of Distortions and Welfare." Trade, Balance of Payments and Growth, J. Bhagwati et al., eds., pp. 69-89, Amsterdam: North Holland, 1971.

CAP Monitor, Agra-Europe (London) Ltd, 1997.

Chambers, R. G. "International Trade, Gross Substitutability, and the Domestic Farm-Retail Price Margin." Eur. R. Agr. Econ. 10 (1983): 33-53.

Chambers, R. G. "On Efficient Redistribution Through Commodity Programs and Neglected Social Cost." Working Paper, University of Maryland, Department of Agricultural and Resource Economics (October 1991).

Dixit, A. K., and V. Norman. Theory of International Trade. Cambridge: Cambridge University Press, 1980.

Feenstra, R. C. "Trade Policy with Several Goods and 'Market Linkages'." J. Int. Econ. 20 (1986): 249-267.

Gardner, B. L. "Efficient Redistribution Through Commodity Markets." Amer. J. Agr. Econ. 65 (May 1983): 225-34.

Lanclos, D. K., and T. W. Hertel. "Endogenous Product Differentiation and Trade Policy: Implications for the U.S. Food Industry.", Amer. J. Agr. Econ. 77 (August 1995): 591-601. 
Lanclos, D. K., T. W. Hertel, and S. Devadoss. " Assessing the Effects of Tariff Reform on U.S. Food Manufacturing Industries: The Role of Imperfect Competition and Intermediate Inputs." Working Paper AERS 95-4, University of Idaho, College of Agriculture (1995).

Moschini, G., and P. Sckokai. "Efficiency of Decoupled Farm Programs Under Distortionary Taxation." Amer. J. Agr. Econ. 76 (August 1994): 362-370.

Neary, P. J.. "Cost Asymmetries in International Subsidy Games: Should Governments Help Winners or Losers?", J. Int. Econ. 37 (1994): 167-196.

Paarlberg, P. L. "Agricultural Export Subsidies and International Goods Trade." Amer. J. Agr. Econ. 77 (February 1995): 119-128.

Wallace, T. D. "Measures of Social Costs of Agricultural Programs." J. Farm. Econ. 44 (May 1962): $580-94$.

\section{Annex: Derivation of equations (23) and (24)}

We focus on equation (24). Equation (23) is obtained in the same manner. Its derivation is not reproduced, but it is available upon request.

The price wedge $p d_{1}-p_{1}=\mu \cdot\left(S_{2} D_{12}-D_{1} S_{22}\right) /\left(D_{12} S_{21}-D_{11} S_{22}\right)$ may be expressed in elasticity form as:

(A1) $\frac{p d_{1}-p_{1}}{p d_{1}}=\mu \cdot \frac{\eta_{D_{12}}-\eta_{S_{22}}}{\eta_{D_{12}} \eta_{S_{21}}-\eta_{D_{11}} \eta_{S_{22}}}=\mu \cdot \frac{1-\eta_{D_{12}} / \eta_{S_{22}}}{\eta_{D_{11}}-\eta_{D_{12}} \eta_{S_{21}} / \eta_{S_{22}}}$ where $\eta_{A_{i}}$ is the price elasticity of $A_{i}$ with respect to the price of good $j$.

The comparative statics of $S_{2}\left(p s_{2}, p d_{1}, w, K_{2}\right)$ and $D_{1}\left(p s_{2}, p d_{1}, w, K_{2}\right)$ may be written as (assuming $d w=d K_{2}=0$ ):

(A2) $d \log S_{2}=\eta_{S_{22}} d \log p s_{2}+\eta_{S_{21}} d \log p d_{1}$

(A3) $d \log D_{1}=\eta_{D_{12}} d \log p s_{2}+\eta_{D_{11}} d \log p d_{1}$ 
Equation (A2) allows us to express $d \log p s_{2}$ in function of $d \log p d_{1}$ and $d \log S_{2}$. Introducing the resulting expression into (A3), one obtains:

(A4) $d \log D_{1}=\left(\eta_{D_{11}}-\eta_{S_{21}} \eta_{D_{12}} / \eta_{S_{22}}\right) \cdot d \log p d_{1}+\eta_{D_{12}} / \eta_{S_{22}} \cdot d \log S_{2}$

Equation (A4) gives the comparative statics of the constrained demand function of good 1, $\hat{D}_{1}\left(p d_{1}, w, S_{2}, K_{2}\right)$, with respect to $p d_{1}$ and $S_{2}$ in elasticity form. Equation (A1) may then be written as:

(A5) $\frac{p d_{1}-p_{1}}{p d_{1}}=\mu \cdot \frac{1-\partial \log \hat{D}_{1}\left(p d_{1}, w, S_{2}, K_{2}\right) / \partial \log S_{2}}{\partial \log \hat{D}_{1}\left(p d_{1}, w, S_{2}, K_{2}\right) / \partial \log p d_{1}}$

The assumption of long-run constant returns to scale implies:

(A6) $\partial \log \hat{D}_{1}\left(p d_{1}, w, S_{2}, K_{2}\right) / \partial \log S_{2}+\partial \log \hat{D}_{1}\left(p d_{1}, w, S_{2}, K_{2}\right) / \partial \log K_{2}=1$

Equation (A5) may thus finally be written as:

(A7) $\frac{p d_{1}-p_{1}}{p d_{1}}=\mu \cdot \frac{\partial \log \hat{D}_{1}\left(p d_{1}, w, S_{2}, K_{2}\right) / \partial \log K_{2}}{\partial \log \hat{D}_{1}\left(p d_{1}, w, S_{2}, K_{2}\right) / \partial \log p d_{1}}$

We now show that expression (A7) is negative (respectively positive) when $D_{1}$ and $K_{2}$ are long-run hicksian complements (respectively substitutes). We define the long-run or unconstrained unit cost function in sector 2 as $c\left(p d_{1}, w, r_{2}\right)$. The zero profit condition in sector 2 is then:

(A8) $c\left(p d_{1}, w, r_{2}\right)=p s_{2}$

From Shephard's lemma, the long-run hicksian demand functions for factors $D_{1}$ and $K_{2}$ are:

(A9) $S_{2} \cdot \frac{\partial c\left(p d_{1}, w, r_{2}\right)}{\partial p d_{1}}=\widetilde{D}_{1}\left(p d_{1}, w, r_{2}\right)$

(A10) $S_{2} \cdot \frac{\partial c\left(p d_{1}, w, r_{2}\right)}{\partial r_{2}}=\widetilde{K}_{2}\left(p d_{1}, w, r_{2}\right)$

By $\log$ differentiation of equations (A8), (A9) and (A10), and assuming $d w=0$, one obtains: 
(A11) $\left[\begin{array}{lll}0 & \theta_{1} & \theta_{K} \\ 1 & \theta_{1} \sigma_{11} & \theta_{K} \sigma_{1 K} \\ 1 & \theta_{1} \sigma_{1 K} & \theta_{K} \sigma_{K K}\end{array}\right]\left[\begin{array}{c}d \log S_{2} \\ d \log p d_{1} \\ d \log r_{2}\end{array}\right]=\left[\begin{array}{c}d \log p s_{2} \\ d \log \widetilde{D}_{1} \\ d \log \widetilde{K}_{2}\end{array}\right]$

where $\theta_{1}$ is the cost share of input $D_{1}, \theta_{K}$ is the cost share of input $K_{2}, \sigma_{11}$ is the unconstrained own elasticity of substitution for input $D_{1}, \sigma_{K K}$ is the unconstrained own elasticity of substitution for input $K_{2}$, and $\sigma_{1 K}$ is the unconstrained Hicks-Allen partial elasticity of substitution between $D_{1}$ and $K_{2}$.

Solving (A11) for $d \log S_{2}, d \log D_{1}$ and $d \log r_{2}$ in terms of $d \log p s_{2}, d \log p d_{1}$ and $d \log K_{2}$, one obtains:

(A12) $d \log S_{2}=-\sigma_{K K} \cdot d \log p s_{2}+\theta_{1}\left(\sigma_{K K}-\sigma_{1 K}\right) \cdot d \log p d_{1}+d \log K_{2}$

(A13) $d \log D_{1}=\left(\sigma_{1 K}-\sigma_{K K}\right) \cdot d \log p s_{2}+\theta_{1}\left(\sigma_{11}+\sigma_{K K}-2 \sigma_{1 K}\right) \cdot d \log p d_{1}+\left(1-\theta_{1} \sigma_{1 K}\right) \cdot d \log K_{2}$

(A14) $d \log r_{2}=\left(1 / \theta_{K}\right) \cdot d \log p s_{2}-\left(\theta_{1} / \theta_{K}\right) \cdot d \log p d_{1}$

Equation (A12) gives an expression of supply elasticities $\eta_{s_{22}}$ and $\eta_{s_{21}}$ in terms of unit cost function parameters, while equation (A13) gives an expression of demand elasticities $\eta_{D_{12}}$ and $\eta_{D_{11}}$. Substituting these expressions into (A1), one yields:

(A15) $\frac{p d_{1}-p_{1}}{p d_{1}}=\mu \cdot \frac{\sigma_{1 K}}{\sigma_{11} \sigma_{K K}-\left(\sigma_{K 1}\right)^{2}}$

The denominator in (A15) is positive due to the convexity in prices of the unconstrained unit cost function. The numerator is negative when $D_{1}$ and $K_{2}$ are long-run hicksian complements (i.e., $\sigma_{1 K}<0$ ) and it is positive when these inputs are long-run hicksian substitutes (i.e., $\left.\sigma_{1 K}>0\right)$

In a similar way, one shows:

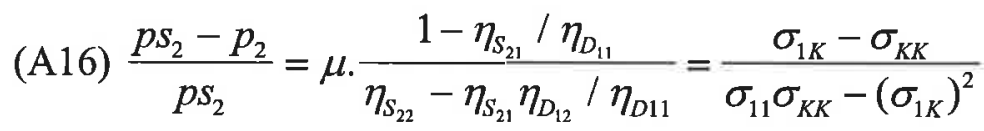




\section{Endnotes}

${ }^{1}$ We are grateful to C. Crampes, C. Le Mouël and P. L. Paarlberg for helpful comments and suggestions.

${ }^{2}$ The analysis is concerned with efficient redistribution to farmers in terms of minimizing the total costs to consumers and taxpayers of achieving a given increase in farmers' surplus. The most efficient way of achieving this objective is clearly a lump-sum transfer. When the latter is not feasible, Moschini and Sckokai show that a decoupled transfer is the most efficient way of transferring income to producers even if this decoupled transfer creates deadweight losses elsewhere in the economy.

${ }^{3}$ The matrix $X_{i j}^{*}$ is positive semi-definite (Dixit and Norman). We will suppose that it is positive definite since we assume that good 1 is a normal input in production of good 2.

${ }^{4}$ The determinant $\Delta$ is positive by the convexity in prices of the restricted profit function in the HVP industry.

${ }^{5}$ Under the assumption that good 1 is a normal input in production of good 2.

${ }^{6}$ Prices $p_{2}$ and $p_{1}$ are fictitious prices. They are introduced in order to characterize the targeting principle consistent optimal policy which should be used to achieve the redistribution objective to HVP producers. Results are sharpened when applied to the particular case of a small open economy, when there is no excess burden of taxation $(\delta=0)$ and the bulk commodity producers' income target is not binding $(\lambda=0)$. In that case, $p_{2}=p d_{2}=p_{2}^{*}, p_{1}=p s_{1}=p_{1}^{*}$, and intervention is required only to achieve the HVP producers' income target acting simultaneously on $p s_{2}$ and $p d_{1}$.

${ }^{7}$ Equation (27) is obtained from post-multiplying (26) by $\left[\pi_{2}^{2}, \pi_{1}^{2}\right]^{1}$ which yields a positive definite quadratic form $(\Delta>0)$. 
${ }^{8}$ The proof is reported in annex.

${ }^{9}$ This inequality is satisfied without ambiguity when $D_{1}$ and $K_{2}$ are long-run hicksian substitutes $\left(\sigma_{1 K}>0\right)$. In the complementarity case, it is satisfied when own effects dominate cross effects, i.e., when $\sigma_{K K}<\sigma_{1 K}<0$.

${ }^{10}$ The proof is reported in annex.

${ }^{11}$ Because of the Leontief assumption, the long-run unit cost function in sector 2, country $\mathrm{H}$ may be written as $c\left(p d_{1}, w, r_{2}\right)=p d / a_{1}+\widetilde{c}\left(w, r_{2}\right)$ where $r_{2}$ are quasi-rents to the specific factor in the HVP industry. The zero profit condition implies $p s_{2}=p d / a_{1}+\widetilde{c}\left(w, r_{2}\right)$, which defines $r_{2}$ as a function of $p s_{2}-p d_{1} / a$ and $w$, i.e., $r_{2}\left(p s_{2}-p d_{1} / a, w\right)$. The profit function in sector 2 may now be written as $\pi^{2}\left(p s_{2}-p d_{1} / a, w, K_{2}\right)$. From Hotelling's lemma, one defines $\quad S_{2}\left(p s_{2}-p d_{1} / a, w, K_{2}\right) \quad$ and $\quad D_{1}\left(p s_{2}-p d_{1} / a, w, K_{2}\right) \quad$ with $S_{2}\left(p s_{2}-p d_{1} / a, w, K_{2}\right)=a \cdot D_{1}\left(p s_{2}-p d_{1} / a, w, K_{2}\right)$.

${ }^{12}$ On this point, see Chambers (1991) who analyzes the general equilibrium incidence of farm programs in the presence of distortionary taxation for a small open economy. 